\title{
Detection of dengue viruses using reverse transcription-loop-mediated isothermal amplification
}

Boon-Teong Teoh, Sing-Sin Sam, Kim-Kee Tan, Jefree Johari, Mohammed Bashar Danlami, Poh-Sim Hooi, Rafi Md-Esa and Sazaly AbuBakar

\begin{abstract}
Background: Early and rapid detection of dengue virus (DENV) infection during the febrile period is crucial for proper patient management and prevention of disease spread. An easy to perform and highly sensitive method is needed for routine implementation especially in the resource-limited rural healthcare settings where dengue is endemic.

Methods: A single-tube reverse transcription-loop-mediated isothermal amplification (RT-LAMP) assay with a set of nine primers was developed for the detection of all four DENV serotypes and their different genotypes. The sensitivity and specificity of the RT-LAMP were evaluated. The clinical applicability of RT-LAMP assay for detection of DENV RNA was assessed in a total of 305 sera of clinically-suspected dengue patients. The test results of RT-LAMP were statistically compared to those of quantitative reverse transcription-polymerase chain reaction (qRT-PCR), IgM- and IgG-capture enzyme-linked immunosorbent assays (ELISA).

Results: Acute DENV infection was confirmed in 171 samples $(n=305) ; 43.3 \%(74 / 171)$ and $46.8 \%(80 / 171)$ of the samples were positive for DENV using RT-LAMP and GRT-PCR, respectively. The combination of RT-LAMP with the dengue IgM and IgG ELISA increased detection of acute DENV infection to 97.7\% (167/171), in comparison to only $70.8 \%$ (121/171) when dengue IgM and IgG ELISA alone were used. The RT-LAMP assays showed high concordance $(K=0.939)$ with the qRT-PCR. The RT-LAMP assay detected up to 10 copies of virus RNA within an hour but $100 \%$ reproducibility (12/12) was achieved with 100 copies. There was no cross reactivity of RT-LAMP with other closely related arboviruses.
\end{abstract}

Conclusion: The RT-LAMP assay developed in this study is sensitive, specific and simple to perform. The assay improved the detection of dengue when used in combination with serological methods.

\section{Background}

Dengue virus (DENV) is a positive-sense single-stranded RNA virus with a genome of $\sim 10.7 \mathrm{~kb}$ in length [1]. There are four antigenically distinct DENV serotypes; DENV-1, DENV-2, DENV-3 and DENV-4 [2] and each serotype contains phylogenetically distinct genotypes [3]. Infection with any of the four serotypes produces a spectrum of clinical illness ranging from mild dengue fever (DF) to severe and fatal dengue hemorrhagic fever (DHF) and hemorrhagic shock syndrome (DSS) [4].

\footnotetext{
* Correspondence: sazaly@um.edu.my

Tropical Infectious Diseases Research and Education Centre (TIDREC), Department of Medical Microbiology, Faculty of Medicine, University of Malaya, Kuala Lumpur 50603, Malaysia
}

Infection with one serotype leads to lifelong protection against homotypic reinfection but only temporary crossprotection against heterotypic infection [5]. Studies have shown that heterotypic secondary infection is associated with higher risk of contracting DHF and DSS [6] possibly through antibody-dependent enhancement $[7,8]$, original antigenic sin $[9,10]$, cytokine storm [11], or autoimmune response $[12,13]$. Currently, an estimated 3.6 billion persons living in dengue-endemic countries are at risk of contracting dengue [14]. Viremic individuals are the main source of infectious virus. Virus is transmitted following mosquito bites of these viremic individuals. A sensitive, easy to perform and rapid method for detection of DENV in viremic febrile patients is therefore of paramount 
importance especially for patient management and immediate vector control measures to prevent large-scale epidemic [15].

Routine laboratory diagnosis of DENV infection in most resource-limited countries is based on the detection of virus-specific antibodies as well as virus isolation. Detection of viral components such as non-structural protein 1 (NS1) and virus genomic RNA are done but mostly in referral or in more well-funded diagnostic laboratories [16-18]. Although virus isolation in C6/36 mosquito cell line has been considered as the "gold standard" for DENV detection, it is costly and timeconsuming as more than 7 days is required to complete the assay $[19,20]$. IgM- and IgG-capture enzyme-linked immunosorbent assays (ELISA) are the most widely used methods to infer DENV infection serologically [21]. However, it requires second convalescent sera for confirmation of test results. It is also not useful during the febrile viremic phase of the infection when there is yet no significant rise in the antibody titers. In addition, antibody cross-reactivity towards other closely related flaviviruses is a common problem [16]. DENV NS1 ELISA, the other known dengue test, is highly sensitive and specific $[22,23]$ but it can be compromised by preexisting NS1-IgG immunocomplexes in the acute stage of secondary DENV infection, which is common in dengue endemic region [24-27]. More recently, molecular techniques to detect virus genomic RNA sequence by reverse transcription-polymerase chain reaction (RT-PCR) and real-time quantitative RT-PCR (qRT-PCR) are gradually being accepted as new standards over virus isolation for the detection of DENV in acute sera [28-32]. The method is highly useful for detection of virus in viremic individuals. The requirement of costly nucleic acid amplification instrument and high level of skill, however, has restricted the application of these methods especially in resource-limited rural healthcare settings.

The loop-mediated isothermal amplification (LAMP) of genomic sequence is a novel method for the detection of nucleic acid with high specificity and sensitivity without the need of specialized equipment [33-35]. The method requires only a heating block or water bath that can maintain constant temperature between 60 to $65^{\circ} \mathrm{C}$ as the nucleic acid amplification reaction can be performed at a single constant temperature. It has been described for the detection of various infectious agents including DENV [36-38]. These earlier reports, however, evaluated their RT-LAMP assays for the detection of DENV infection with a small clinical sample size $(<100)$ and using the C-prM gene [38] or serotype-specific regions of the 3' untranslated region (UTR) [36,37] as the amplification targets. In the present study, we described an improved method for the development and application of the RT-LAMP assay for the detection of DENV infection in freshly obtained dengue-suspected patient samples in actual clinical laboratory setting of a hospital in dengue endemic environment.

\section{Methods \\ Dengue viruses}

A total of 11 reference DENV strains (four strains of DENV-1, genotype I, II, III and sylvatic; two strains of DENV-2, Asian I and cosmopolitan; three strains of DENV-3, genotype I, II and III; two strains of DENV-4, subgenotype IIa and IIb) were used in this study [30,39-41]. All the viruses were archived in the University Malaya Medical Centre (UMMC) Diagnostic Virology Laboratory repository. The isolates at passage 1 were used to inoculate C6/36 (Aedes albopictus) mosquito cells for one week and virus RNA was extracted from the infected cell culture supernatant.

\section{Clinical samples}

The study obtained ethics approval from the UMMC Medical Ethics Committee (Ethics Committee/IRB Reference Number: 908.11). The study was conducted during the period from October to December 2012. A total of 305 serum samples from patients clinically suspected with DENV infection were obtained. All clinical samples were taken as part of standard patient care. The samples were divided in the laboratory to be used for routine diagnosis by serological assays and evaluation of the RTLAMP assay developed in this study.

\section{RNA extraction}

Total RNA was extracted from $140 \mu \mathrm{l}$ of infected culture supernatant or patient serum samples using QIAamp Viral RNA Mini Kit (Qiagen, Germany), following the manufacturer's protocol. All RNA extraction was done manually. The RNA was eluted in $60 \mu \mathrm{l}$ of nuclease-free water and stored at $-80^{\circ} \mathrm{C}$ until needed.

\section{Design of DENV-specific RT-LAMP assay primers}

The DENV-specific primers used for RT-LAMP assay were designed from the 3'UTR of the DENV genome. The 3'UTR nucleotide sequences of each DENV serotypes were retrieved from GenBank. Multiple sequence alignment of the 3'UTR sequences was performed using Clustal X 2.0 [42]. A set of nine primers comprising four outer, four inner, and one loop primers that recognize seven distinct regions on the target sequence was designed according to the criteria described by Notomi et al. [33] (Table 1 and Additional file 1). The coverage of the RT-LAMP primers was validated by evaluating the assay using viral RNA extracted from the different DENV strains, as described above. 
Table 1 RT-LAMP primers used for the rapid detection of DENV

\begin{tabular}{ll}
\hline Primer $^{\mathbf{a}, \mathbf{b}}$ & Sequence $\left(\mathbf{5}^{\prime} \boldsymbol{\rightarrow} \mathbf{3}^{\prime}\right)$ \\
\hline F3/134 & CAAACCGTGCTGCCTGT \\
F3/2 & TGAGTAAACTATGCAGCCTGT \\
B3/123 & ACCTGTTGATTCAACAGCACC \\
B3/4 & ACCTGTTGGATCAACAACACC \\
FIP/123 & AGGGGTCTCCTCTAACCRCTAGTCTTTCAAACCRTGGAAGCTG \\
& TACGC \\
FIP/4 & AGGGGTCTCCTCTAACCRCTAGTCTITITGCCACGGAAGCTGT \\
& ACGC \\
BIP/123 & ACAGCATATTGACGCTGGGARAGACGTTCTGTGCCTGGAATGA \\
& TGCTG \\
BIP/4 & ACAGCATATTGACGCTGGGARAGACGCTCTGTGCCTGGATTGA \\
BLP/1234 & CAGAGG \\
\hline
\end{tabular}

${ }^{\mathrm{a}} \mathrm{F} 3$ forward outer primer, $B 3$ backward outer primer, FIP forward inner primer, $B I P$ backward inner primer, BLP backward loop primer.

${ }^{\mathrm{b}}$ Number (1-4) after the slash (/) represents DENV serotype (e.g. F3/134, forward outer primer for DENV-1, -3 and -4$)$.

\section{RT-LAMP assay}

The RT-LAMP was performed in a final reaction volume of $25 \mu \mathrm{l}$ using a Loopamp RNA Amplification Kit (Eiken Chemical Co. Ltd., Japan) added with 20 pmol each of inner primers $\mathrm{FIP} / 123, \mathrm{FIP} / 4, \mathrm{BIP} / 123$, and $\mathrm{BIP} / 4 ; 2.5$ pmol each of outer primers F3/134, F3/2, B3/123, and B3/ 4; 20 pmol of loop primer BLP/1234; $1 \mu$ l of Fluorescent Detection Reagent (Eiken Chemical Co. Ltd., Japan); and $5 \mu \mathrm{l}$ of the extracted RNA template. A positive control using 1000 copies (determined by qRT-PCR) of DENV RNA extracted from culture supernatant and a negative control (nuclease-free water) were included in each run. The RT-LAMP reactions were incubated at $63^{\circ} \mathrm{C}$ for $80 \mathrm{~min}$ and inactivated at $80^{\circ} \mathrm{C}$ for $5 \mathrm{~min}$ in LA-500 Loopamp real-time turbidimeter (Eiken Chemical Co. Ltd., Japan). The turbidity of RT-LAMP reaction was spectrophotometrically recorded at $650 \mathrm{~nm}$ every $6 \mathrm{~s}$. The threshold time $(\mathrm{Tt})$ value for positivity by RT-LAMP was determined when the turbidity increased above the threshold value, which was fixed at 0.07 absorbance units. The RT-LAMP amplification was also visually monitored for color change. Positive reaction turned the reaction mix green and fluoresces under the white light and UV irradiation, respectively. The reaction mix remained orange and non-fluorescent in the absence of amplification.

\section{Specificity of RT-LAMP assay}

The specificity of the RT-LAMP amplification was assessed by single site restriction enzyme digestion of the amplified DNA fragments using BanII [36]. Following overnight digestion at $37^{\circ} \mathrm{C}$, the undigested and digested RT-LAMP-amplified DNA fragments were electrophoresed on a $2 \%$ agarose gel in Tris-acetate-EDTA buffer.
The gel was stained with GelRed (Biotium Inc., US) and visualized using a Gel Doc 2000 (Bio-Rad Laboratories, Inc., US). The digested DNA fragments were sequenced using the loop primer BLP/1234. The specificity of the DENV RT-LAMP primers was evaluated against another three closely related arboviruses common in the region; Japanese encephalitis virus (JEV), Chikungunya virus (CHIKV), and Sindbis virus (SINV).

\section{Sensitivity of RT-LAMP assay}

The sensitivity of RT-LAMP assay was assessed using a panel of serially diluted viral RNA (1000, 100, 60, and 10 copy numbers) extracted from culture supernatant. The sensitivity test of RT-LAMP was repeated twelve times. The viral RNA used was quantitated using the genesig Real-Time qRT-PCR DENV Detection Kit (PrimerDesign Ltd., UK). The qRT-PCR assay standard plot, ranged from 10 to $10^{6}$ RNA copies, was made by preparing a 10 -fold serial dilution of the genesig DENV RNA standard. The genesig DENV RNA standard was a synthetic RNA template with known copy number. The qRT-PCR was performed in a final volume of $20 \mu \mathrm{l}$ containing $10 \mu \mathrm{l}$ of real time master mix, $1 \mu \mathrm{l}$ of probe/primer mix, $4 \mu \mathrm{l}$ of nuclease-free water, and $5 \mu$ l of diluted RNA. Quantitative PCR measurement was performed using StepOnePlus real time PCR system (Applied Biosystems, USA) according to the following condition: $10 \mathrm{~min}$ at $55^{\circ} \mathrm{C}, 8 \mathrm{~min}$ at $95^{\circ} \mathrm{C}$ followed by 50 cycles of amplification $\left(10 \mathrm{~s}\right.$ at $95^{\circ} \mathrm{C}, 60 \mathrm{~s}$ at $60^{\circ} \mathrm{C}$ ). Raw data was analyzed with StepOne Software v2.2.1 to determine copy number based on the threshold cycles $(\mathrm{Ct})$. The efficiency of the qRT-PCR was measured from the slope of standard curve.

\section{Evaluation of RT-LAMP assay}

The clinical applicability of a single-tube RT-LAMP assay for detection of DENV RNA was assessed in a total of 305 serum samples freshly obtained from dengue-suspected patients. The qRT-PCR, as described above, was used as a reference assay for the detection of DENV RNA in the samples. In addition, the samples were simultaneously screened for the presence of anti-dengue IgM using the SD Dengue IgM Capture ELISA kit (Standard Diagnosis Inc., Korea). The IgM-negative samples were further screened for the presence of anti-dengue IgG using the SD Dengue IgG Capture ELISA kit (Standard Diagnosis Inc., Korea). The test results of RT-LAMP, qRT-PCR, and ELISA were compared. Acute DENV infection was confirmed by the positive detection of anti-DENV IgM by ELISA and/or the presence of DENV RNA detected by qRT-PCR assay. Serum sample tested positive only for anti-DENV IgG was identified as indicative of past DENV infection.

In this study, the results obtained by molecular diagnosis of dengue were not used for the standard patient care as the molecular assay was still being developed. The qRT- 
PCR was used only as research tool in the reference laboratory. Currently, only the serological methods were approved for routine clinical diagnosis of dengue at the UMMC.

\section{Statistical analysis}

All statistical analysis was performed using IBM SPSS Statistics, version 21 (IBM Corporation, New York, United States). The degree of agreement between RT-LAMP and qRT-PCR test results was measured by kappa value ( $\mathrm{k}$ ). Chi-square test (McNemar's exact test, two-tailed) was performed to evaluate and compare the sensitivity of all molecular and serological methods used. In the present study, the $\mathrm{p}$-value $<0.001$ was used to suggest significant results. The diagnostic performance of RT-LAMP assay as compared to qRT-PCR was calculated using webbased CEBM Statistics Calculator (http://ktclearinghouse. ca/cebm/toolbox/statscalc).

\section{Results}

Design of DENV-specific RT-LAMP assay primers

In order to develop the single-tube RT-LAMP assay for detection of all four DENV serotypes, a set of nine primers comprising four outer (F3/134, F3/2, B3/123, and B3/4), four inner (FIP/123, FIP/4, BIP/123, and BIP/4), and one loop primers $(\mathrm{BLP} / 1234)$ were designed. This was done using the alignment of the conserved 3'UTR regions of DENV genome (Table 1 and Additional file 1). Results shown in Figure 1 suggested that the RT-LAMP primers detected the entire panel of 11 available reference DENV strains.

\section{Specificity of RT-LAMP assay}

No cross-reactivity of the RT-Lamp assay was observed with all other three closely related arboviruses common in the region, including JEV, CHIKV and SINV (Figure 1).

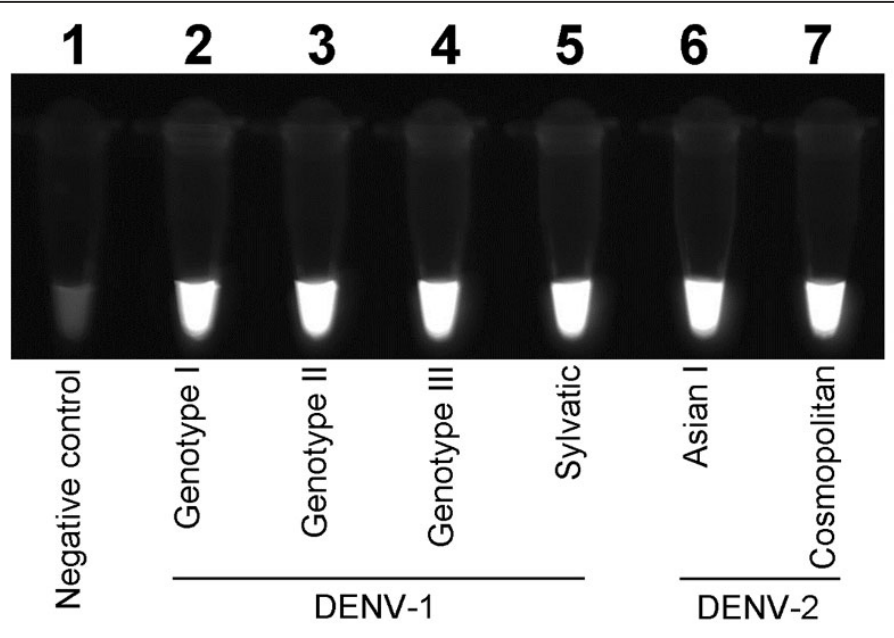

\section{$\begin{array}{llllllll}8 & 9 & 10 & 11 & 12 & 13 & 14 & 15\end{array}$}

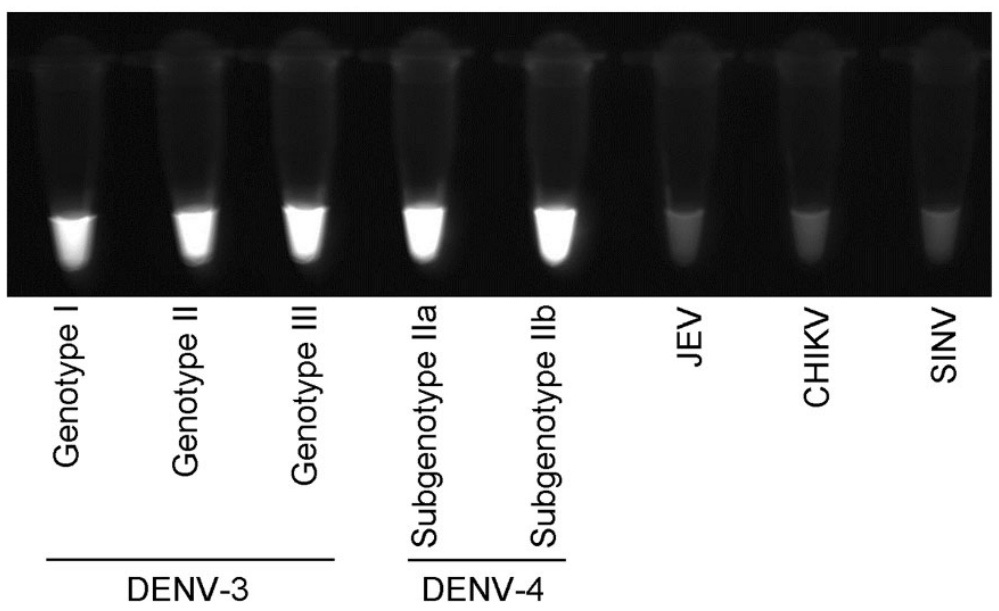

Figure 1 Visual observation of fluorescence in RT-LAMP reactions under UV light. Tube 1, negative control; tube 2-5, DENV-1 genotype I, II, III and sylvatic, respectively; tube 6-7, DENV-2 Asian I and cosmopolitan, respectively; tube 8-10, DENV-3 genotype I, II and III, respectively; tube 11-12, DENV-4 subgenotype Ila and IIb, respectively; tube 13-15, JEV, CHIKV and SINV, respectively. 
The specificity of the assay was also verified by restriction enzyme BanII digestion on the amplified DNA fragments of all four DENV serotypes. As shown in Figure 2, the undigested and digested DNA fragments were observed as ladder-like and two-band patterns, respectively [36,37]. The sizes of the digested DNA fragments were in agreement with the expected size for each serotype; $129 \mathrm{bp}$ and $233 \mathrm{bp}$ for DENV-1, $135 \mathrm{bp}$ and $231 \mathrm{bp}$ for DENV-2, 129 bp and 231 bp for DENV-3, as well as $141 \mathrm{bp}$ and $231 \mathrm{bp}$ for DENV-4. Nucleotide sequencing of the $231 \mathrm{bp}$ and $233 \mathrm{bp}$ digested DNA fragments confirmed that the RT-LAMP amplified nucleotide sequences were specific to DENV (data not shown).

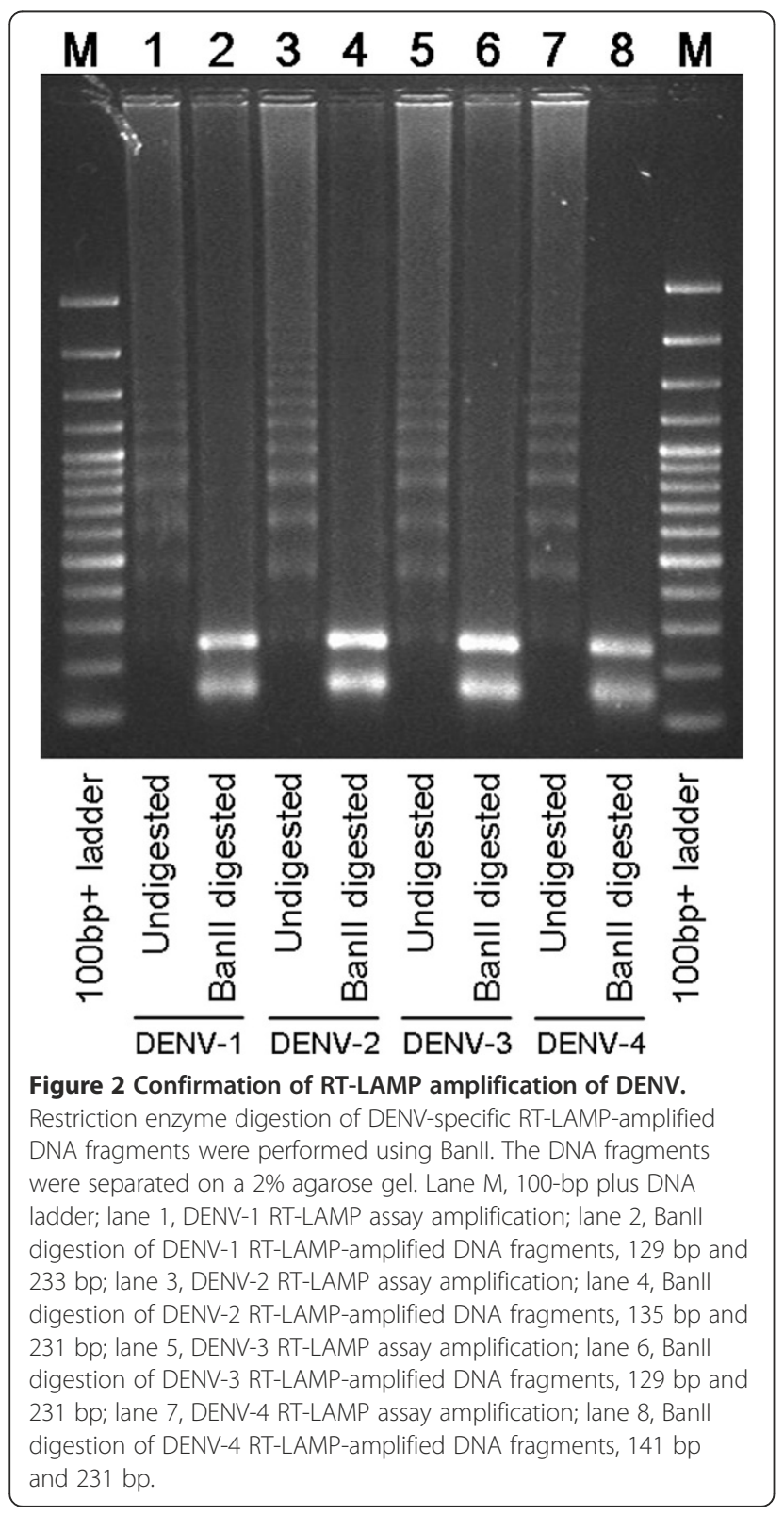

\section{Sensitivity of RT-LAMP assay}

The sensitivity of RT-LAMP assay was determined by repeated independent testing on a panel of serially diluted viral RNA extracted from culture supernatant with known copy number (Figure 3). The number of positive detection by RT-LAMP assays $(n=12)$ for the DENV RNA with copy numbers of $1000,100,60$, and 10 were $100 \%$ (12 of 12), $100 \%$ (12 of 12), $75 \%$ (9 of 12), and 25\% (3 of 12), respectively, with the mean time threshold $(\mathrm{Tt})$ of $46.97 \pm$ $2.28 \mathrm{~min}, 53.67 \pm 1.77 \mathrm{~min}, 53.78 \pm 2.89 \mathrm{~min}, 53.28 \pm$ $5.04 \mathrm{~min}$, respectively. The RT-LAMP assay detected up to 10 copies of RNA but $100 \%$ (12 of 12) reproducibility was achieved with at least 100 copies of RNA.

\section{Evaluation of RT-LAMP assay}

The RT-LAMP assay for detection of DENV RNA was evaluated by testing on a total of 305 fresh serum samples of clinically dengue-suspected patients. The findings of RT-LAMP were compared to those obtained by qRTPCR. Of the 305 samples, 282 were first serum samples while 23 were second samples collected at 1 to 5 days from the first sample. Out of 305 samples, acute dengue infection was confirmed in $171(56.1 \%)$ by either qRTPCR or dengue IgM ELISA, or both (Table 2). Five out of the 171 samples $(2.9 \%)$ were identified as secondary DENV infection as virus RNA and dengue-specific IgG were detected in the absence of dengue IgM. Seven samples were identified as past DENV infection as only dengue IgG was tested positive.

The diagnostic performance of the RT-LAMP in comparison with qRT-PCR assay is summarized in Table 3. The RT-LAMP assay detected DENV genome in 74 of $171(43.3 \%)$ of the acute dengue samples compared to

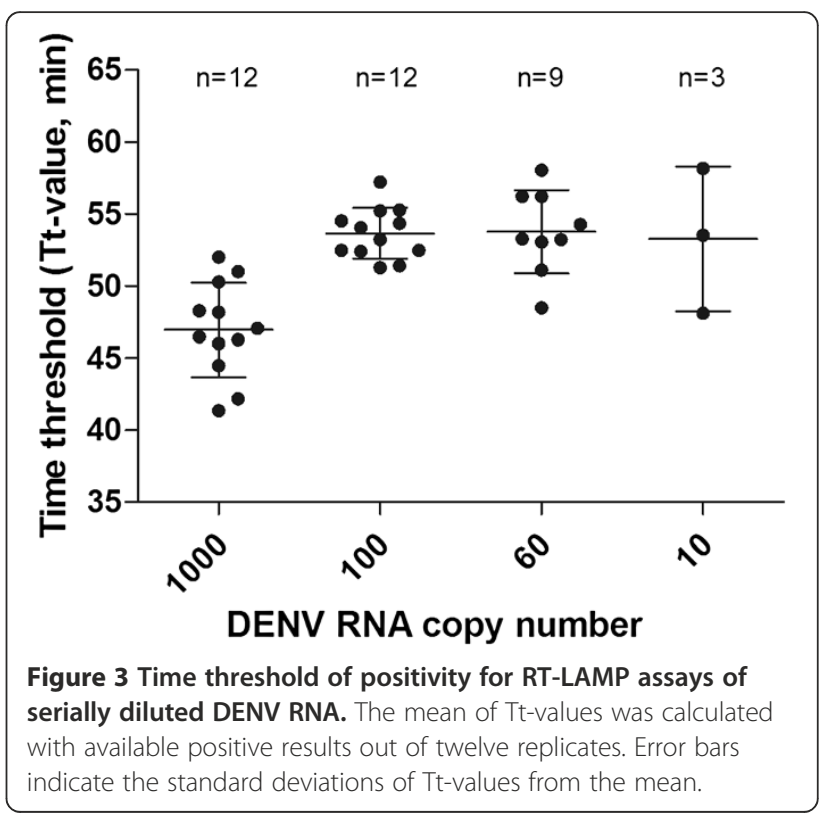


Table 2 Summary of dengue detection in serum samples from clinically dengue-suspected patients in UMMC using RT-LAMP, qRT-PCR, IgM and IgG ELISA

\begin{tabular}{|c|c|c|c|c|c|c|}
\hline \multirow[b]{3}{*}{ Assays } & \multirow[b]{3}{*}{ Results $^{c}$} & \multicolumn{2}{|c|}{ IgM ELISA } & \multicolumn{3}{|c|}{ IgG ELISA ${ }^{b}$} \\
\hline & & Positive & Negative & Positive & Negative & Not-tested \\
\hline & & n (\%) & n (\%) & n (\%) & n (\%) & n (\%) \\
\hline \multirow[t]{4}{*}{ RT-LAMP } & Positive & $23(30.7)$ & $52(69.3)$ & $5(6.7)$ & $40(53.3)$ & $30(40.0)$ \\
\hline & $\left(n=75^{d}\right)$ & & & & & \\
\hline & Negative & $93(40.4)$ & 137 (59.6) & $7^{f}(3.1)$ & $130(56.5)$ & $93(40.4)$ \\
\hline & $(n=230)$ & & & & & \\
\hline \multirow[t]{4}{*}{ qRT-PCR } & Positive & $25^{\mathrm{a}}(31.3)$ & $55^{\mathrm{a}}(68.7)$ & $5(6.3)$ & $43(53.7)$ & $32(40.0)$ \\
\hline & $\left(\mathrm{n}=80^{\mathrm{e}}\right)$ & & & & & \\
\hline & Negative & $91^{\mathrm{a}}(40.4)$ & 134 (59.6) & $7^{f}(3.1)$ & $127(56.5)$ & $91(40.4)$ \\
\hline & $(n=225)$ & & & & & \\
\hline
\end{tabular}

${ }^{a}$ Acute DENV infection was confirmed in 171 samples.

${ }^{\mathrm{b}}$ Dengue IgG ELISA was only performed on 182 (out of 189) dengue IgM negative samples.

${ }^{\mathrm{C}}$ Agreement of results between RT-LAMP and qRT-PCR, $\mathrm{K}=0.939$.

${ }^{\mathrm{d}}$ One of RT-LAMP positive samples were tested negative by qRT-PCR

${ }^{\text {e}} \mathrm{Six}$ of qRT-PCR positive samples were tested negative by RT-LAMP.

fDENV RNA was tested negative by both RT-LAMP and qRT-PCR in 7 samples.

80 of $171(46.8 \%)$ by qRT-PCR assay (Table 2). These two methods, however, showed high concordance with kappa value of $0.939(\mathrm{p}<0.001)$. DENV RNA was tested negative in 6 samples by RT-LAMP but positive by qRTPCR. All of these samples contained $<50$ copies of RNA per reaction (Figure 4). In this study, one sample that was tested positive by RT-LAMP but negative by qRTPCR or serological methods was considered as false positive. The combination of RT-LAMP with the dengue IgM and IgG ELISA resulted in a significant increase $(\mathrm{p}<0.001)$ in sensitivity to $97.7 \%$ (167 of 171$)$ in comparison to using dengue IgM and IgG ELISA alone which had sensitivity of $70.8 \%$ (121 of 171) (Figure 5).

\section{Discussion}

In the present study, a single-tube RT-LAMP assay was developed with a set of nine primers targeted at the highly conserved regions of DENV 3'UTR of the reported global DENV strains. We demonstrated that the RT-LAMP assay detected a panel of DENV strains from different DENV genotypes circulating in Malaysia and many other dengue endemic countries in Southeast Asia [30,39-41]. There was no cross reactivity of RT-LAMP with other closely related arboviruses. The RT-LAMP assay was as sensitive as the qRT-PCR for DENV detection in the viremic serum samples. In this study, the RT-LAMP assay is positioned as a complementary tool for the routine serology test in a reference diagnostic laboratory.

The RT-LAMP assay developed here differs from those reported earlier in at least two major areas [36-38]. Parida et al. (2005) developed a four-tube RT-LAMP assay which employed serotype-specific primers targeting the proximal half of the 3'UTR of DENV genome [36]. The four-tube reaction system required four separate reactions to be performed for each sample. Therefore, it is not costeffective for routine diagnosis particularly in the hospital setting where the interest is simply in knowing if the patient has dengue. Recently, Lu et al. developed a singletube reaction system for the detection of DENV infection using RT-LAMP primers derived from the C-prM gene [38]. The C-prM gene, however, was relatively less conserved among all four DENV serotypes (inter-serotype) in comparison to the 3'UTR (unpublished data). Thus, the primers designed based on the C-prM gene may not give a good coverage for all four DENV serotypes and their genotypes. In many dengue hyperendemic countries, multiple DENV genotypes of all four serotypes co-circulate [30,39-41]. In our study, we used the combination of primers targeting the highly conserved region of DENV 3' UTR. The nine primers were generated to be useful to

Table 3 Diagnostic performance of RT-LAMP assay against qRT-PCR assay in serum samples from clinically dengue-suspected patients in UMMC

\begin{tabular}{|c|c|c|c|c|c|c|c|}
\hline \multirow[b]{2}{*}{ Assay } & \multirow[b]{2}{*}{ Results } & \multicolumn{2}{|c|}{ qRT-PCR } & \multirow[t]{2}{*}{ Sensitivity\% $(95 \% \mathrm{Cl})$} & \multirow[t]{2}{*}{ Specificity\% (95\% Cl) } & \multirow[t]{2}{*}{ PPV\% $(95 \% \mathrm{Cl})$} & \multirow[t]{2}{*}{ NPV\% $(95 \% \mathrm{Cl}$} \\
\hline & & Pos & Neg & & & & \\
\hline \multirow[t]{2}{*}{ RT-LAMP } & Pos & 74 & 1 & $92.5(84.6-96.5)$ & $99.6(97.5-99.9)$ & $98.7(92.8-99.8)$ & 97.4 (94.4-98.8) \\
\hline & $\mathrm{Neg}$ & 6 & 224 & & & & \\
\hline
\end{tabular}

PPV positive predicted value, NPV negative predicted value, $\mathrm{Cl}$ confidence interval, Pos positive, Neg negative. 


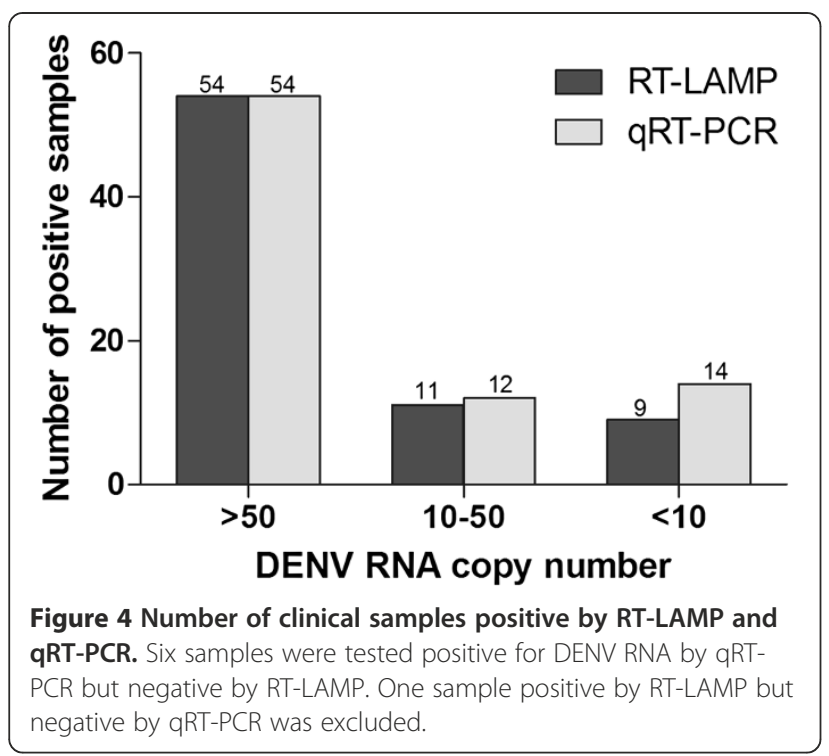

accommodate the viral diversity present in the region. We showed here that all the 11 different reference DENV strains from 10 DENV genotypes were detected with the RT-LAMP primers designed in the study.

The RT-LAMP assay developed in this study has a detection limit of at least 100 copies of viral RNA (Figure 3). We defined the detection limit in this study as the lowest amount of template detectable with $100 \%$ reproducibility throughout the repeated testing. Other similar studies have reported detection limit of lower than 100 copies but with lack of information on the

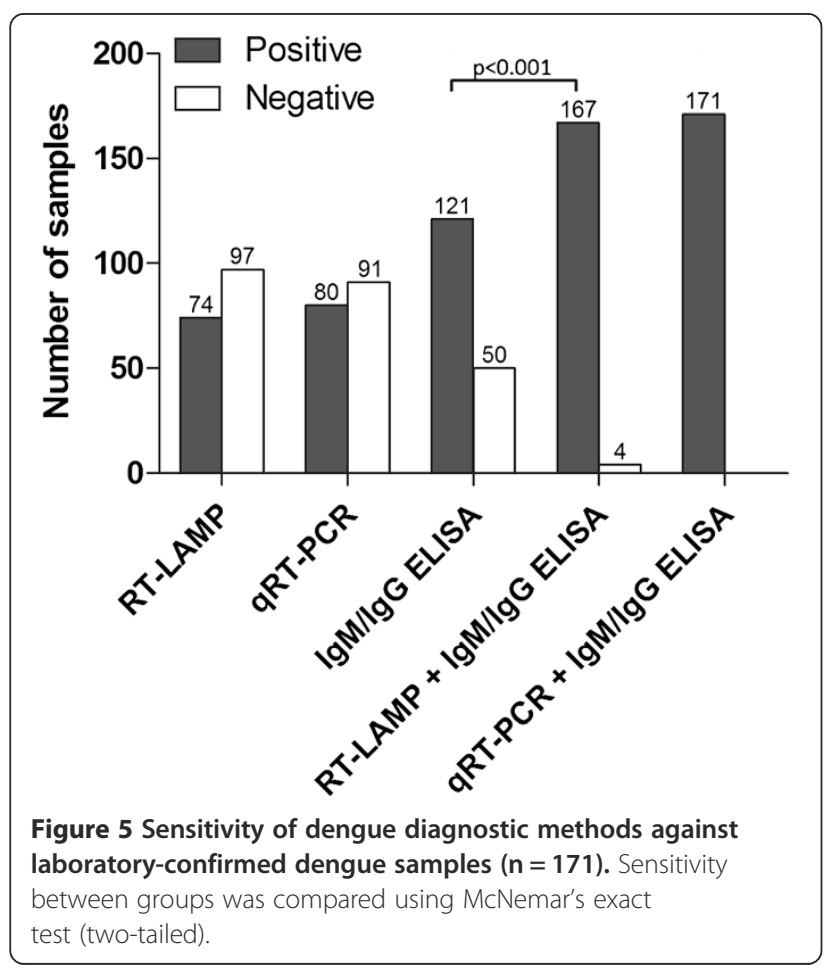

confidence level $[37,38]$. Our RT-LAMP assay was able to detect up to as few as 10 copies of viral RNA, but with reduced reproducibility. The viral load was inversely proportional to the antibody titer according to the day of onset of fever. Low viral load ( $<100$ viruses) is usually accompanied with the rise of antibody titer $[43,44]$. The detection of DENV using RT-LAMP regardless of the viral load could be completed within 1 hour making the assay a rapid tool for early dengue diagnosis.

Here, the RT-LAMP assay for DENV detection was prospectively evaluated for the first time with a large number of clinical serum samples $(n=305)$ from dengue-suspected patients. The performance of the RTLAMP assay was validated by simultaneous testing of the samples using real time qRT-PCR, which is known as the most sensitive and specific method for the detection of viral RNA [45]. In our study, both the RT-LAMP and qRT-PCR assays showed comparable sensitivity for the detection of DENV in patients' sera $(\kappa=0.939)$, even though the sensitivity of RT-LAMP was slightly lower than that of qRT-PCR. Similar findings have been reported in several other studies for the evaluation of LAMP assay when compared against the qPCR $[46,47]$. The RT-LAMP assay in this study gave possibly six false negative and one false positive results. The false negative detection could be caused by low viral load, below the detection limit of RT-LAMP. However, this could also reflect false positive detection of the qRT-PCR. This could be verified by culturing the samples for virus isolation. Similarly, the false positive RT-LAMP result could be a true positive but need to be verified by virus isolation.

Currently, in most dengue endemic region where resources are limited, early diagnosis of dengue relies very much on the clinical presentations. A number of other infections, however, can present with almost similar features especially during the early febrile phase. Rapid confirmation of dengue is important to ensure proper management of patients and appropriate outbreak prevention measures. Currently, serological assay is the most common method used to confirm DENV infection. In our study, using actual clinical samples when febrile dengue patients first visit to the hospital, $46.8 \%$ (80 of 171) of the specimen received indicated that the patients were viremic with the absence of IgM or IgG (Figure 5). The RT-LAMP or qRT-PCR, when used in combination with ELISA, increased the diagnostic coverage of febrile dengue patient to more than $97 \%$. The early detection of viremic individuals allows for immediate intervention to prevent further spread of dengue by encouraging the patient to take precaution to prevent from mosquito bites. In addition, it allows the patient to have sufficient warning to immediately come back to hospital if warning signs of impending severe dengue develops. 


\section{Conclusions}

The RT-LAMP assay developed in our study showed high sensitivity and specificity comparable to qRT-PCR for detection of DENV in clinical samples. The singletube RT-LAMP assay utilized a primer set with coverage for all the reported DENV strains particularly those common in the region. Implementation of the RTLAMP assay into routine dengue diagnosis to complement the antibody detection would greatly enhance the diagnostic coverage of suspected dengue cases without the need for costly equipment and reagents. The RTLAMP assay developed in this study is sensitive, specific and simple to perform, and in combination with the ELISA is a promising detection tool for early dengue diagnosis in rural clinics and field situation where resources are limited.

\section{Additional file}

Additional file 1: Figure S1. Map of RT-LAMP primers in alignment with the DENV 3'UTR consensus sequences. The arrows indicate the orientation of primers in $5^{\prime}$ to $3^{\prime}$ direction.

\section{Competing interests}

All authors have no competing interests.

\section{Authors' contributions}

$B T T, S S S, K K T, J J, M B D$, and SAB conceived the study and participated in its design and coordination. BTT designed the RT-LAMP primers. BTT and SSS performed sample preparation and RNA extraction. BTT, SSS, KKT, PSH, and RME performed the RT-LAMP, QRT-PCR and ELISA assays. BTT, SSS, KKT, and PSH analyzed the results. SSS carried out the statistical analysis. BTT, SSS and $S A B$ drafted the manuscript. $S A B$ is the principle investigator of this study. All authors read and approved the final manuscript.

\section{Acknowledgments}

The study was financially supported by European Union's Seventh Framework Programme (FP7/2007-2013) under the grant agreement 282589 DengueTools.

Received: 21 March 2013 Accepted: 16 August 2013

Published: 21 August 2013

\section{References}

1. Henchal EA, Putnak JR: The dengue viruses. Clin Microbiol Rev 1990, 3(4):376-396.

2. Russell PK, Nisalak A: Dengue virus identification by the plaque reduction neutralization test. J Immunol 1967, 99(2):291-296.

3. Holmes EC, Burch SS: The causes and consequences of genetic variation in dengue virus. Trends Microbiol 2000, 8(2):74-77.

4. Gubler DJ: Dengue and dengue hemorrhagic fever. Clin Microbiol Rev 1998, 11(3):480-496.

5. Kurane I, Ennis FE: Immunity and immunopathology in dengue virus infections. Semin Immunol 1992, 4(2):121-127.

6. Sam SS, Omar SF, Teoh BT, Abd-Jamil J, Abubakar S: Review of dengue hemorrhagic fever fatal cases seen among adults: a retrospective study. PLoS Negl Trop Dis 2013, 7(5):e2194.

7. Halstead SB: Observations related to pathogensis of dengue hemorrhagic fever. VI. Hypotheses and discussion. Yale J Biol Med 1970, 42(5):350-362.

8. Kouri GP, Guzman MG, Bravo JR, Triana C: Dengue haemorrhagic fever/ dengue shock syndrome: lessons from the Cuban epidemic, 1981. Bull World Health Organ 1989, 67(4):375-380.

9. Halstead SB, Rojanasuphot S, Sangkawibha N: Original antigenic sin in dengue. Am J Trop Med Hyg 1983, 32(1):154-156.
10. Mongkolsapaya J, Dejnirattisai W, Xu XN, Vasanawathana S,

Tangthawornchaikul N, Chairunsri A, Sawasdivorn S, Duangchinda T, Dong T, Rowland-Jones S, Yenchitsomanus PT, McMichael A, Malasit P, Screaton G: Original antigenic sin and apoptosis in the pathogenesis of dengue hemorrhagic fever. Nat Med 2003, 9(7):921-927.

11. Pang T, Cardosa MJ, Guzman MG: Of cascades and perfect storms: the immunopathogenesis of dengue haemorrhagic fever-dengue shock syndrome (DHF/DSS). Immunol Cell Biol 2007, 85(1):43-45.

12. Markoff LJ, Innis BL, Houghten R, Henchal LS: Development of crossreactive antibodies to plasminogen during the immune response to dengue virus infection. J Infect Dis 1991, 164(2):294-301.

13. Falconar AK: The dengue virus nonstructural-1 protein (NS1) generates antibodies to common epitopes on human blood clotting, integrin/adhesin proteins and binds to human endothelial cells: potential implications in haemorrhagic fever pathogenesis. Arch Virol 1997, 142(5):897-916.

14. Gubler DJ: The economic burden of dengue. Am J Trop Med Hyg 2012, 86(5):743-744

15. Wilder-Smith A, Renhorn KE, Tissera H, Abu Bakar S, Alphey L, Kittayapong P, Lindsay S, Logan J, Hatz C, Reiter P, Rocklov J, Byass P, Louis VR, Tozan Y, Massad E, Tenorio A, Lagneau C, L'Ambert G, Brooks D, Wegerdt J, Gubler D: DengueTools: innovative tools and strategies for the surveillance and control of dengue. Glob Health Action 2012, 5:17273. doi:10.3402/gha.v5i0.17273.

16. Guzman MG, Kouri G: Advances in dengue diagnosis. Clin Diagn Lab Immunol 1996, 3(6):621-627.

17. Guzman MG, Kouri G: Dengue diagnosis, advances and challenges. Int J Infect Dis 2004, 8(2):69-80.

18. Shu PY, Huang JH: Current advances in dengue diagnosis. Clin Diagn Lab Immunol 2004, 11(4):642-650.

19. Igarashi A: Isolation of a Singh's Aedes albopictus cell clone sensitive to Dengue and Chikungunya viruses. J Gen Virol 1978, 40(3):531-544.

20. Tesh RB: A method for the isolation and identification of dengue viruses, using mosquito cell cultures. Am J Trop Med Hyg 1979, 28(6):1053-1059.

21. Innis BL, Nisalak A, Nimmannitya S, Kusalerdchariya S, Chongswasdi V, Suntayakorn S, Puttisri P, Hoke CH: An enzyme-linked immunosorbent assay to characterize dengue infections where dengue and Japanese encephalitis co-circulate. Am J Trop Med Hyg 1989, 40(4):418-427.

22. Young PR, Hilditch PA, Bletchly C, Halloran W: An antigen capture enzymelinked immunosorbent assay reveals high levels of the dengue virus protein NS1 in the sera of infected patients. J Clin Microbiol 2000, 38(3):1053-1057.

23. Alcon S, Talarmin A, Debruyne M, Falconar A, Deubel V, Flamand M: Enzyme-linked immunosorbent assay specific to Dengue virus type 1 nonstructural protein NS1 reveals circulation of the antigen in the blood during the acute phase of disease in patients experiencing primary or secondary infections. J Clin Microbiol 2002, 40(2):376-381.

24. Hang VT, Nguyet NM, Trung DT, Tricou V, Yoksan S, Dung NM, Van Ngoc T, Hien T, Farrar J, Wills B, Simmons CP: Diagnostic accuracy of NS1 ELISA and lateral flow rapid tests for dengue sensitivity, specificity and relationship to viraemia and antibody responses. PLoS Negl Trop Dis 2009, 3(1):e360.

25. Lima Mda R, Nogueira RM, Schatzmayr HG, Dos Santos FB: Comparison of three commercially available dengue NS1 antigen capture assays for acute diagnosis of dengue in Brazil. PLoS Negl Trop Dis 2010, 4(7):e738.

26. Koraka P, Burghoorn-Maas CP, Falconar A, Setiati TE, Djamiatun K, Groen J, Osterhaus AD: Detection of immune-complex-dissociated nonstructural-1 antigen in patients with acute dengue virus infections. J Clin Microbiol 2003, 41(9):4154-4159.

27. Lapphra K, Sangcharaswichai A, Chokephaibulkit K, Tiengrim S, Piriyakarnsakul W, Chakorn T, Yoksan S, Wattanamongkolsil L, Thamlikitkul V: Evaluation of an NS1 antigen detection for diagnosis of acute dengue infection in patients with acute febrile illness. Diagn Microbiol Infect Dis 2008, 60(4):387-391.

28. Lanciotti RS, Calisher CH, Gubler DJ, Chang GJ, Vorndam AV: Rapid detection and typing of dengue viruses from clinical samples by using reverse transcriptase-polymerase chain reaction. J Clin Microbiol 1992, 30(3):545-551.

29. Seah CL, Chow VT, Tan HC, Can YC: Rapid, single-step RT-PCR typing of dengue viruses using five NS3 gene primers. J Virol Methods 1995, 51(2-3):193-200.

30. AbuBakar S, Wong PF, Chan YF: Emergence of dengue virus type 4 genotype IIA in Malaysia. J Gen Virol 2002, 83(Pt 10):2437-2442. 
31. Laue T, Emmerich P, Schmitz H: Detection of dengue virus RNA in patients after primary or secondary dengue infection by using the TaqMan automated amplification system. J Clin Microbiol 1999, 37(8):2543-2547.

32. Shu PY, Chang SF, Kuo YC, Yueh YY, Chien L, Sue CL, Lin TH, Huang JH: Development of group- and serotype-specific one-step SYBR green Ibased real-time reverse transcription-PCR assay for dengue virus. J Clin Microbiol 2003, 41(6):2408-2416.

33. Notomi T, Okayama H, Masubuchi $H$, Yonekawa $T$, Watanabe $K$, Amino $N$, Hase T: Loop-mediated isothermal amplification of DNA. Nucleic Acids Res 2000, 28(12):E63.

34. Mori Y, Nagamine K, Tomita N, Notomi T: Detection of loop-mediated isothermal amplification reaction by turbidity derived from magnesium pyrophosphate formation. Biochem Biophys Res Commun 2001, 289(1):150-154.

35. Tomita N, Mori Y, Kanda H, Notomi T: Loop-mediated isothermal amplification (LAMP) of gene sequences and simple visual detection of products. Nat Protoc 2008, 3(5):877-882.

36. Parida M, Horioke K, Ishida H, Dash PK, Saxena P, Jana AM, Islam MA, Inoue S, Hosaka N, Morita K: Rapid detection and differentiation of dengue virus serotypes by a real-time reverse transcription-loop-mediated isothermal amplification assay. J Clin Microbiol 2005, 43(6):2895-2903.

37. Li S, Fang M, Zhou B, Ni H, Shen Q, Zhang H, Han Y, Yin J, Chang W, Xu G, Cao G: Simultaneous detection and differentiation of dengue virus serotypes 1-4, Japanese encephalitis virus, and West Nile virus by a combined reverse-transcription loop-mediated isothermal amplification assay. Virol J 2011, 8:360.

38. Lu X, Li X, Mo Z, Jin F, Wang B, Zhao H, Shan X, Shi L: Rapid identification of chikungunya and dengue virus by a real-time reverse transcriptionloop-mediated isothermal amplification method. Am J Trop Med Hyg 2012, 87(5):947-953.

39. Teoh BT, Sam SS, Abd-Jamil J, AbuBakar S: Isolation of ancestral sylvatic dengue virus type 1, Malaysia. Emerg Infect Dis 2010, 16(11):1783-1785.

40. Kobayashi N, Thayan R, Sugimoto C, Oda K, Saat Z, Vijayamalar B, Sinniah M, Igarashi A: Type-3 dengue viruses responsible for the dengue epidemic in Malaysia during 1993-1994. Am J Trop Med Hyg 1999, 60(6):904-909.

41. Chee HY, AbuBakar S: Phylogenetic investigation of dengue virus type-2 isolated in Malaysia. Dengue Bull 2003, 27:100-107.

42. Thompson JD, Gibson TJ, Plewniak F, Jeanmougin F, Higgins DG: The CLUSTAL_X windows interface: flexible strategies for multiple sequence alignment aided by quality analysis tools. Nucleic Acids Res 1997 25(24):4876-4882.

43. Levi JE, Tateno AF, Machado AF, Ramalho DC, De Souza VA, Guilarde AO, De Rezende Feres VC, Martelli CM, Turchi MD, Siqueira JB Jr, Pannuti CS: Evaluation of a commercial real-time PCR kit for detection of dengue virus in samples collected during an outbreak in Goiania, Central Brazil, in 2005. J Clin Microbiol 2007, 45(6):1893-1897.

44. Kong YY, Thay $C H$, Tin TC, Devi S: Rapid detection, serotyping and quantitation of dengue viruses by TaqMan real-time one-step RT-PCR. J Virol Methods 2006, 138(1-2):123-130.

45. Ratcliff RM, Chang G, Kok T, Sloots TP: Molecular diagnosis of medical viruses. Curr Issues Mol Biol 2007, 9(2):87-102.

46. Postel A, Letzel T, Frischmann S, Grund C, Beer M, Harder T: Evaluation of two commercial loop-mediated isothermal amplification assays for detection of avian influenza $\mathrm{H} 5$ and $\mathrm{H} 7$ hemagglutinin genes. J Vet Diagn Invest 2010, 22(1):61-66

47. Saito R, Misawa Y, Moriya K, Koike K, Ubukata K, Okamura N: Development and evaluation of a loop-mediated isothermal amplification assay for rapid detection of Mycoplasma pneumoniae. J Med Microbiol 2005, 54(Pt 11):1037-1041.

doi:10.1186/1471-2334-13-387

Cite this article as: Teoh et al.: Detection of dengue viruses using reverse transcription-loop-mediated isothermal amplification. BMC Infectious Diseases 2013 13:387.

\section{Submit your next manuscript to BioMed Central and take full advantage of:}

- Convenient online submission

- Thorough peer review

- No space constraints or color figure charges

- Immediate publication on acceptance

- Inclusion in PubMed, CAS, Scopus and Google Scholar

- Research which is freely available for redistribution

Submit your manuscript at www.biomedcentral.com/submit
C BioMed Central 